\section{Commentary: New methods for old problems?}

\author{
Derrick Y. Tam, MD, ${ }^{\mathrm{a}}$ Malak Elbatarny, MD, ${ }^{\mathrm{b}}$ and \\ Stephen E. Fremes, MD, MSc, FRCSC
}

As health care costs continue to rise in almost all jurisdictions, understanding the cost consequences of our procedures and complications becomes increasingly important. Postoperative atrial fibrillation (POAF) is seen in $25 \%$ to $40 \%$ of our patients after cardiac surgery. ${ }^{1}$ Although POAF is often paroxysmal and temporary, sequelae may be devastating and long-lasting, both in health care costs and adverse events and quality of life. In this subanalysis of the Randomized On/Off Bypass Follow-up (ROOBY) study, Almassi and colleagues ${ }^{2}$ compared cost and effectiveness outcomes of 551 patients who had undergone coronary artery bypass grafting $(\mathrm{CABG})$ with new-onset $\mathrm{POAF}$ with 1552 without POAF at 5 years. They showed that, after risk adjustment, 5-year all-cause mortality was not statistically different in patients with POAF and without POAF (odds ratio, 1.19; 99\% confidence interval, 0.81-1.75). Outcomes in patients with POAF have been well studied, and the conclusions regarding the association of POAF with late outcomes remain controversial ${ }^{3}$ - differences between studies may largely be related to the definition of $\mathrm{AF}$ used. $^{4}$ In contrary, less is known about the short- and long-term costs of POAF. In this study, Almassi and colleagues ${ }^{2}$ showed that costs were, on average, more than $\$ 15,000$ USD greater for patients with POAF in the first year but accumulated costs from years 2 through 5 were similar.

The interpretation of the cost-analysis conducted by Almassi and colleagues ${ }^{2}$ must acknowledge some important limitations. The authors chose to analyze costs over 5 years

\footnotetext{
From the ${ }^{a}$ Division of Cardiac Surgery, Department of Surgery, Schulich Heart Centre, Sunnybrook Health Sciences Centre, and ${ }^{b}$ Division of Cardiac Surgery, Department of Surgery, University of Toronto, Toronto, Ontario, Canada.

Disclosures: Authors have nothing to disclose with regard to commercial support.

Dr Tam is supported by a CIHR Fellowship (Canada). Dr Fremes is supported by the Bernard S. Goldman Chair in Cardiovascular Surgery (Toronto, Ontario, Canada).

Received for publication Nov 22, 2019; revisions received Nov 22, 2019; accepted for publication Nov 25, 2019; available ahead of print Dec 12, 2019.

Address for reprints: Stephen E. Fremes, MD, MSc, FRCSC, Schulich Heart Centre, Sunnybrook Health Sciences Centre, 2075 Bayview Ave, Room H4 05, Toronto, Ontario, M4N 3M5 Canada (E-mail: Stephen.fremes@sunnybrook.ca).

J Thorac Cardiovasc Surg 2021;161:1814-5

0022-5223/\$36.00

Copyright (c) 2019 by The American Association for Thoracic Surgery

https://doi.org/10.1016/j.jtcvs.2019.11.102
}

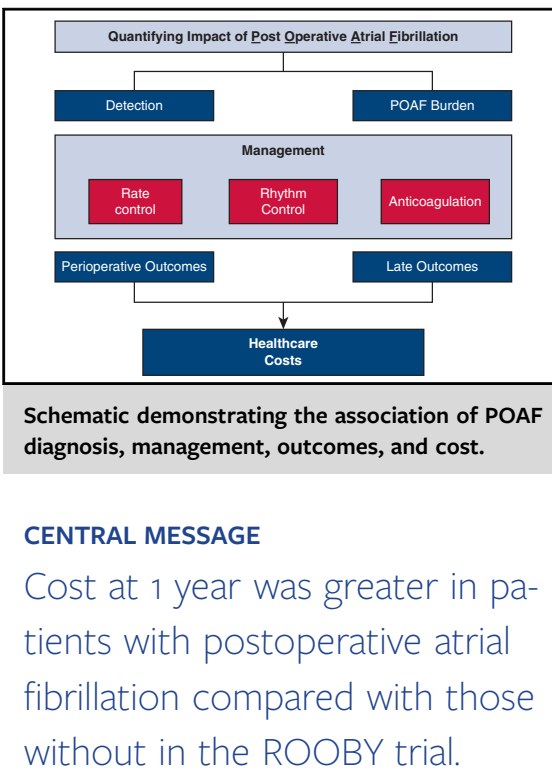

in 1-year periods and suggest that cost accumulation occurred mainly in the first year, driven by the index hospitalization costs. However, the use of phase-based costing, a technique that originated from cancer costing, may be more appropriate in POAF. ${ }^{5}$ Phase-based costing allows for the empirical determination of distinct periods of rapid cost accumulation that may be intrinsic to the natural history of certain disease states. Outside of cancer, this technique has been applied to coronary disease, heart failure, and atrial fibrillation and has demonstrated that these disease states are associated with patterns of rapid cost accumulation interspersed with periods of lower costs, the former likely associated with complications or death. Indeed, the authors here suggest that there may be distinct phases of cost accumulation in their analysis; in particular, an early phase of cost accumulation (from time of POAF development to 1 year) followed by a lull in cost accumulation between years 2 and 5 .

The use of a 5-year time horizon is another limitation of this study -in patients with POAF that does not resolve or in those who suffer nonfatal but long-lasting sequelae, POAF becomes a lifetime disease that incurs lifetime costs. While following patients in a clinical trial indefinitely until all patients die is impractical and unwieldy, the use of phasebased costing techniques allows for the modeling of a disease over a lifetime. Indeed, work by Tawfik and colleagues ${ }^{6}$ using administrative data out of Ontario have demonstrated this in patients with incident diagnosis of new-onset atrial fibrillation and clinical events of minor stroke/transient ischemic attack, ischemic strokes, and intra- or extracranial 
hemorrhage. The monthly costs associated with fatal clinical events were high $(\$ 42,871 \mathrm{CAD})$, and those who experienced moderate or severe ischemic strokes had the greatest long-term costs. ${ }^{7}$ Although Almassi and colleagues did perform risk-adjusted analyses for costs, presenting the results of the variables associated with costs would have been instructive. The same regression techniques can be applied in phase-based costing to determine drivers of costs in each empirically determined phase which, in turn, may have important health policy implications.

The authors should be commended for testing the chosen outcomes at a $P$ value of .01 , rather than .05 , to minimize the risk of a type 1 error. Given the totality of the data, late outcomes are likely affected with POAF. That said, the optimal management is still unclear. The completed Cardiothoracic Surgical Trials Network studies did not determine whether a rhythm or rate control strategy is preferred in patients with POAF. ${ }^{1}$ It is also uncertain whether the outcomes are related to the disease itself or the treatment, particularly anticoagulation. The Anticoagulation for New-Onset Post-Operative Atrial Fibrillation After CABG (PACES) trial aims to examine the benefit of oral anticoagulants in addition to antiplatelet therapy in patients with POAF within 7 days of CABG (NCT04045665).

Despite these limitations, the authors should be congratulated on their efforts to better understand the costs associated with POAF, as this work represents the first step in understanding a common and potentially costly/expensive problem. The use of a more advanced statistical modeling technique may provide additional relevant information to help us better understand the cost of POAF, and certainly we hope that others would consider applying these newer methods to the old problems of counting costs.

\section{References}

1. Gillinov AM, Bagiella E, Moskowitz AJ, Raiten JM, Groh MA, Bowdish ME et al. Rate control versus rhythm control for atrial fibrillation after cardiac surgery. N Engl J Med. 2016;374:1911-21.

2. Almassi GH, Hawkins RB, Bishawi M, Shroyer AL, Hattler B, Quin JA, et al New-onset postoperative atrial fibrillation impact on 5-year clinical outcomes and costs. J Thorac Cardiovasc Surg. 2021;161:1803-10.e3.

3. Filardo G, Ailawadi G, Pollock BD, da Graca B, Phan TK, Thourani V, et al Postoperative atrial fibrillation: sex-specific characteristics and effect on survival. J Thorac Cardiovasc Surg. 2020;159:1419-25.e1.

4. Filardo G, Pollock BD, da Graca B, da Graca B, Phan TK, Thourani V, et al. Underestimation of the incidence of new-onset post-coronary artery bypass grafting atrial fibrillation and its impact on 30-day mortality. J Thorac Cardiovasc Surg. 2017; 154:1260-6.

5. Wijeysundera HC, Wang X, Tomlinson G, Ko DT, Krahn MD. Techniques for estimating health care costs with censored data: an overview for the health services researcher. Clinicoecon Outcomes Res. 2012;4:145-55.

6. Tawfik A, Wodchis WP, Pechlivanoglou P, Hoch J, Husereau D, Krahn M. Using phase-based costing of real-world data to inform decision-analytic models for atrial fibrillation. Appl Health Econ Health Policy. 2016;14:313-22.

7. Bennell MC, Qiu F, Micieli A, Ko DT, Dorian P, Atzema CL, et al. Identifying predictors of cumulative healthcare costs in incident atrial fibrillation: a populationbased study. J Am Heart Assoc. 2015;4:884. 